\title{
ANALISIS FLUKTUASI BEBAN TERAHADAP EFISIENSI GENERATOR SINKRON DI PT. PEMBANGKIT LISTRIK PALEMBANG JAYA
}

\author{
Ichsan Refaldi ${ }^{1}$, Yuslan Basir ${ }^{2}$, Dyah Utari Yusa Wardhani ${ }^{3}$ \\ ${ }^{1}$ Program Studi Teknik Elektro, Fakultas Teknik, Universitas Tridinanti Palembang, Indonesia \\ Email: ${ }^{1}$ ichsanrefaldia@gmail.com ${ }^{2}$ yuslanbasir.1958@gmail.com, ${ }^{3}$ dyahutari@univ-tridinanti.ac.id
}

Coauthor : $\underline{\text { dyahutari@univ-tridinanti.ac.id }}$

\begin{abstract}
ABSTRAK
Generator sinkron merupakan sebuah objek vital bagi suatu pembangkitan tenaga listrik. Kinerja sebuah generator sinkron dapat diukur dengan perhitungan efisiensi perbandingan antara daya input pada generator dan daya output generator. PT. Pembangkit Listrik Palembang Jaya memiliki generator sinkron yang tersambung secara sinkronisasi pararel yang dihidupkan secara nonstop atau terus menerus. Suatu efisiensi generator sinkron dapat dipengaruhi oleh jumlah pembebanan dan faktor daya berupa naik turunnya nilai cos phi pembebanan. Menurunnya faktor daya (Cos phi) akan mengakibatkan turunnya sebuah efisiensi. PT. PLPJ menggunakan nilai Cos phi 0.85 dan untuk nilai cos phi optimal pada generator PT. PLPJ sebesar 0.90. Semakin besarnya pembebanan maka akan semakin turunnya sebuah efisiensi. begitu pula sebaliknya, semakin kecilnya pembebanan maka akan naiknya efisiensi.
\end{abstract}

Kata Kunci: Generator sinkron, Pembangkit Listrik, Efisiensi, ETAP 12.6.

\begin{abstract}
ABSTRACK
Synchronous generator is a vital object for an electric power generation. The performance of a synchronous generator can be measured by calculating the efficiency of the ratio between the input power of the generator and the generator's output power. PT. The Palembang Jaya Power Plant has a synchronous generator that is connected in parallel synchronization which is turned on non-stop or continuously. A synchronous generator efficiency can be influenced by the amount of loading and the power factor in the form of fluctuations in the value of cos phi loading. The decrease in power factor (Cos phi) will result in a decrease in efficiency. PT. PLPJ uses the Cos phi value of 0.85 and for the optimal cos phi value on the generator PT. PLPJ is 0.9. The greater the load, the lower the efficiency. and vice versa, the smaller the load, the higher the efficiency.
\end{abstract}

Keyword : Synchronous Generator, Power Plants, Efficiency, ETAP 12.6.

\section{PENDAHULUAN}

PLTMG merupakan singkatan dari pembangkit listrik tenaga mesin gas yang menggunakan sumber tenaga berupa gas alam. Jenis pembangkit ini menggunakan sebuah mesin gas yang sistem kerjanya mirip dengan mesin mobil untuk menggerakan generator listrik yang mengubah energi mekanik menjadi energi listrik. Terdapat 2 unit generator sinkron yang digunakan Berkapasitas 14 MW (2 x 7 ) yang setelahnya akan disalurkan ke trafo daya dari $11 \mathrm{kV}$ menjadi $20 \mathrm{kV}$ (Step up). Pembangkit listrik ini akan memasok jaringan $20 \mathrm{kV}$ milik PT PLN (Persero) yang akan diatur oleh PLN UPB Sumbagsel Rayon Kenten dan berjalan paralel dengan sistem kelistrikan yang ada. PT. PLPJ melayani 3 titik pembebenan yang akan didistribusikan ke penyulang yaitu Airbus, Fokker, Dan Boeing, dan sebagian lainnya akan didistribusikan rumah-rumah sekitaran sematang borang.

Pembebanan PT PLPJ diatur oleh unit Pengatur Beban (UPB). Unit UPB inilah yang akan mengatur besaran pembagian beban pada masing-masing pembangkit tenaga listrik melalui sistem jaringan yang terhubung antara pusat beban dan pembangkit tenaga listrik. Pada saat beban listrik berubah-ubah (Fluktuasi), maka biasanya akan mempengaruhi kinerja dari sebuah 
generator. Semakin tinggi kebutuhan listrik dan semakin tinggi pula beban yang dibangkitkan maka kerja geneator semakin menurun. Maka dari itu, pembangkit listrik harus menghasilkan kapasitas yang besar agar kebutuhan listrik tercukupi. Namun, sehubungan dengan besarnya permintaan beban dan terjadinya sebuah fluktuasi. Maka generator akan mengalami sebuah penurunan efisiensi.

Penelitian tentang perhitungan efisiensi generator dengan data nilai rata-rata daya yang dibangkitkan generator PLTU Rembang unit 10 dan 20 dalam 24 jam selama 10 hari dilakukan oleh Cahyadi [1]. Pada penelitian tersebut didapat hasil bahwa nilai dari efisiensi generator unit 10 dan 20 PLTU rembang mengalami penurunan sebesar $\pm 5 \%$. Pada tahun 2018, Hidayat [2] melakukan penelitian mengenai pengaruh beban terhadap efisiensi generator pada PLTU PT. Lestari Banten Energi. didapatkan hasil rata-rata efisiensi perhari pada generator tersebut berkisar 98\%- 99\%. Penelitian Muharrir dan Ibnu Hajar [3] melakukan terhadap generator pada PLTP unit 2 Kamojang yang harus beroperasi diatas $90 \%$ agar dapat mensupply energi listrik ke jaringan $150 \mathrm{kV}$. Jika generator beroperasi dengan efisiensi dibawah $80 \%$ maka energi yang dialirkan tidak maksimal karena banyak energi listrik yang hilang akibat rugi-rugi pada generatordidapatkan efisiensi rata-rata generator unit 2 sebesar 92,89\%. Apabila dibandingkan dengan efisiensi generator secara desain sebesar $98,4 \%$, nilai efisiensi generator unit 2 Kamojang mengalami penurunan sebesar 5,51\%. M. Noer [4] melakukan penelitian untuk mengetahui nilai efisiensi generator dan rugi menggunakan software MATLAB pada PLTG Borang. rugi daya terkecil pada saat beban puncak adalah 0,0112 MW dan rugi daya terbesar pada saat beban puncak adalah $0,0136 \mathrm{MW}$

Berdasarkan latar belakang di atas permasalahan yang akan diangkat dalam penelitian ini yaitu :

(1) Bagaimana pengaruh fluktuasi beban terhadap efisiensi generator

(2) Bagaimana perbandingan hasil analisa efisiensi generator saat terjadinya beban puncak atau diluar beban puncak.

(3) Bagaimana efisiensi pada tiap-tiap penyulang karena dampak fluktuasi pembebanan generator.

Pada penelitian ini bertujuan untuk mengetahui dampak fluktuasi pembebanan terhadap efisiensi generator sinkron milik PT Pembangkit Listrik Palembang Jaya. Penelitian ini dilakukan dengan simulasi pada ETAP 12.6 dengan mengikuti pedoman berdasarkan pada aplikasi WOIS yang tertera pada monitoring operator dan dilakukan sebuah perhitungan dalam 2 hari/24 jam pada tiaptiap penyulang dalam 30 menit sekali.

\section{Generator sinkron}

Tegangan output dan arus dari generator sinkron merupakan tegangan bolak-balik, karena hal tersebut, generator sinkron juga disebut dengan generator AC. Generator AC memiliki sebuah perbedaan dari generator DC, kumparan jangkar ada pada bagian rotor yang terletak di antara kutub magnet yang tetap di tempat dengan diputar oleh tenaga mekanik. Sedangkan pada generator sinkron merupakan kebalikannya, dimana kumparan jangkar disebut dengan kumparan stator karena berada pada tempat yang tetap. Sedangkan kumparan rotor Bersama-sama dengan kutub magnet diputar oleh tenaga mekanik[5]. Disebut dengan generator sinkron karena kecepatan perputaran pada rotor generator adalah sama dengan perputaran medan megnet. Kecepatan Sinkron ini didapatkan dari perputaran rotor dengan kutub magnet yang sama dengan medan putar pada stator[6]

\section{ETAP (Electrical Transient Analysis Program) 12.6}

Electric Transient and Analysis Program merupakan suatu perangkat lunak yang mendukung sistem tenaga listrik. Perangkat ini mampu bekerja dalam keadaan offline untuk simulasi tenaga listrik, online untuk pengelolaan data real-time atau digunakan untuk mengendalikan sistem secara real-time. Fitur yang terdapat di dalamnya pun bermacam-macam antara lain fitur yang digunakan untuk menganalisa pembangkitan tenaga listrik, sistem transmisi maupun sistem distribusi tenaga listrik. Analisa tenaga listrik yang dapat dilakukan ETAP antara lain: [10] 
1. Analisa aliran daya

2. Analisa hubung singkat

3. Arc Flash Analysis

4. Analisa kestabilan transien, dll.

Dalam menganalisa tenaga listrik, suatu single line diagram merupakan notasi yang disederhanakan untuk sebuah sistem tenaga listrik tiga fasa. Sebagai ganti dari representasi saluran tiga fasa yang terpisah, digunakanlah sebuah konduktor. Hal ini memudahkan dalam pembacaan diagram maupun dalam analisa rangkaian. Elemen elektrik seperti misalnya pemutus rangkaian, transformator, kapasitor, bus bar maupun konduktor lain dapat ditunjukkan dengan menggunakan simbol yang telah distandardisasi untuk diagram saluran tunggal. ETAP memiliki 2 macam standar yang digunakan untuk melakukan analisa kelistrikan, ANSI dan IEC[10]

\section{METODE PENELITIAN}

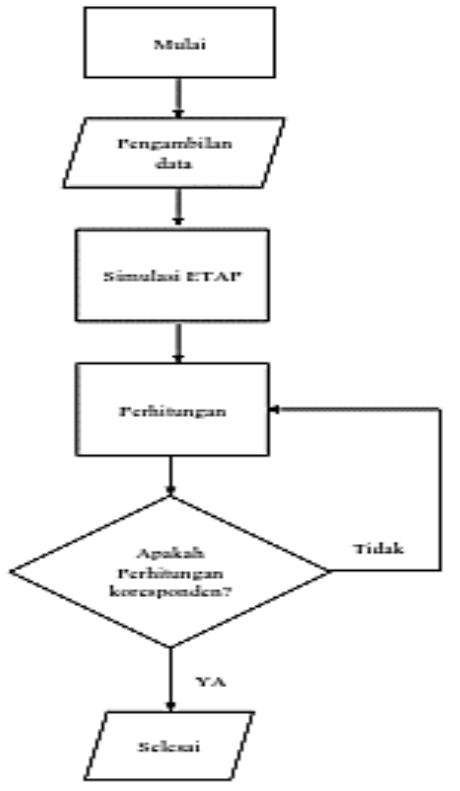

\section{Gambar 1. Flowchart penelitian}

\section{Impedansi}

Impedansi atau biasa disebut dengan hambatan (Z) adalah nilai resistansi yang terukur pada kutub sinyal jack pada alat elektronik. Semakin besar hambatan (impedansi) maka akan makin besar tegangan yang dibutuhkan. Beberapa sumber mengatakan bahwa impedansi merupakan hasil reaksi hambatan (R) dan kapasitas elektron ( c Kapasistansi) secara bersamaan.

$\mathrm{Z}=\frac{V}{I \cdot \sqrt{3}}$

Dimana :

$\mathrm{Z}=$ Impedansi $(\Omega)$

$\mathrm{V}=$ Tegangan Sumber (Volt)

$\mathrm{I}=$ Arus (ampere)

$\sqrt{3}=$ Menunjukkan 3 fhasa

$\mathrm{R}=\mathrm{Z}$ ' $\mathrm{x} \cos \phi$ 


\section{Rugi-rugi Generator Sinkron}

Rugi-rugi generator listrik sebagian dapat ditemukan dengan antara percobaan beban nol dan percobaan block rotor. Percobaan beban nol dapat menentukan rugi-rugi rotasi generator. Pada saat generator dalam keadaan berbeban, seluruh daya listrik generator digunakan untuk mengatasi rugi-rugi tembaga dan rugi mekanik. dalam sistem konversi energi listrik yaitu dalam pengoperasian generator, total daya yang diberikan adalah sama dengan total daya yang diterima. Dan juga kerugian daya yang diberikan adalah sama dengan kerugian daya yang diterima.

\section{Rugi Tembaga}

Rugi-rugi tembaga merupakan belitan stator dari kawat aluminium yang biasa disebut dengan $I_{2} R$ yang dimana menunjukkan besaran daya yang berubah menjadi panas oleh tahanan dari konduktor tembaga atau aluminium. Total kerugian $\mathrm{I}_{2} \mathrm{R}$ adalah jumlah antara rugi $\mathrm{I}_{2} \mathrm{R}$ primer (stator) dan rugi $\mathrm{I}_{2} \mathrm{R}$ (rotor). Pada umumnya rugi-rugi belitan ini berkisar antara $30 \%$ dari total pada beban penuh dengan persamaan :

$\Sigma \mathrm{P}$ rugi-rugi $($ Rugi Tembaga $)=\mathrm{I}^{2} \mathrm{R}$

Rugi Beban Penuh $=\frac{\text { Rugi Tembaga }}{30 \%}$

\section{Rugi Mekanik}

Rugi-rugi mekanik merupakan rugi-rugi antara gesekan dan angina yang dipakai dalam motor listrik untuk menanggulangi gesekan batalan poros, gesekan sikat melawan komutator atau slipring, gesekan dari bagian antara yang berputar terhadap angina, terutama pada daun kipas pendingin. Rugi-rugi mekanik dianggap konstan dari beban nol hingga beban penuh. Besaran rugi mekanik sekitar $20 \%$ dari rugi total pada beban penuh dengan persamaan.

P $m($ Rugi Mekanik $)=20 \% \times$ Rugi Beban Penuh

\section{Rugi Besi}

Besar rugi besi adalah sekitar 20 sampai $30 \%$ dari rugi total pada beban penuh yang dijabarkan dengan persamaan berikut :

$\mathrm{Pb}($ Rugi Besi $)=30 \% \times$ Rugi beban penuh.

$\Sigma$ Rugi Total $=$ Rugi Tembaga + Rugi Mekanik+ Rugi Besi

\section{Efisiensi Generator}

Sebuah kinerja dari generator sinkron dapat dilhat dengan melakukan perhitungan efisiensi generator yang merupakana sebuah perbandingan diantara daya pada output generator dengan daya input. Yang dimana daya masukan untuk generator berupa daya mekanik dan daya keluarannya berupa daya listrik. Seperti halnya dengan mesin-mesin listrik lainnya dengan dapat dituliskan dalam persamaan berikut :

$\eta=\frac{P_{\text {out }}}{P_{\text {in }}} \times 100 \%$

Dimana :

$\begin{array}{ll}\mathrm{P}_{\text {in }} & =\mathrm{P}_{\text {out }}+\sum \mathrm{P}_{\text {rugi-rugi }} \\ \mathrm{P}_{\text {out }} & =\text { daya keluaran } \\ \mathrm{P}_{\text {in }} & =\text { daya masukan }\end{array}$

$\mathrm{P}_{\text {Out }}=\mathrm{V} \cdot \mathrm{I} \cdot \cos \varphi$ 
$\mathrm{P}_{\text {Out }}=3 . \mathrm{V}_{\mathrm{ph}} \cdot \mathrm{I}_{\mathrm{ph}} \cdot \cos \varphi$ (10) [9]

Dimana :

$\begin{array}{ll}\mathrm{P}_{\text {Out }} & =\text { Daya keluaran pada terminal Generator (Watt) } \\ \mathrm{V}_{\mathrm{ph}} & =\text { Tegangan perfasa pada terminal generator (Volt) } \\ \mathrm{I}_{\mathrm{ph}} & =\text { arus perfasa pada beban generator (Ampere) } \\ \cos \varphi & =\text { Faktor daya }\end{array}$

Apabila pada pengaplikasian pada generator 3 fasa maka rumus $\mathrm{P}_{\text {Out }}$ dikalikan dengan 3.

\section{Data Sistem Pembangkitan PT. PLPJ}

PT. PLPJ memiliki 2 unit generator sinkron yang tersambung secara sinkronisasi pararel dengan tegangan $11 \mathrm{kV}$ yang lalu dinaikkan menjadi $20 \mathrm{kV}$ dengan 2 unit trafo daya (Step up) yang selanjutnya akan didistribusikan ke pembebanan yang dilayani PT PLPJ sebanyak 3 titik penyulang dan sebagian lainnya didistribusikan ke masyarakat sekitar pembangkitan. Untuk menyelesaikan permasalahan yang diangkat, maka penelitian ini membutuhkan data-data yang digunakan dalam sebuah perhitungan.

Tabel 1. Spesifikasi Generator Sinkron

\begin{tabular}{ll}
\hline Merk & WARTSILA \\
\hline Tipe & AVK DIG 167 e/8 \\
Buatan & German \\
Daya & $9680 \mathrm{kVA}$ \\
Jumlah Phasa & $3 \mathrm{Phasa}$ \\
Frekuensi & $50 \mathrm{~Hz}$ \\
Arus Armatur & $508.1 \mathrm{~A}$ \\
Tegangan Armatur & $11000 \mathrm{~V}$ \\
Arus Medan & $260 \mathrm{~A}$ \\
Tegangan Eksitasi & $250 \mathrm{~V}$ \\
Faktor Daya & 0.80 \\
RPM & 750 \\
\hline
\end{tabular}

Tabel 2. Spesifikasi Transformator Daya

\begin{tabular}{ll}
\hline Merk & TRAFOINDO \\
\hline Buatan & Indonesia \\
Daya & $9680 \mathrm{KVA}$ \\
Jumlah Phasa & $3 \mathrm{Phasa}$ \\
Frekuensi & $50 \mathrm{~Hz}$ \\
Arus High Voltage & $279,44 \mathrm{~A}$ \\
Arus Low Voltage & $508.07 \mathrm{~A}$ \\
Tegangan High Voltage & $20000 \mathrm{~V}$ \\
Tegangan Low Voltage & $11000 \mathrm{~V}$ \\
Impedansi & $9.0 \%$ \\
Standard & IEC 60076 \\
\hline
\end{tabular}

\section{Single Line Diagram PT.PLPJ Dengan ETAP 12.6}

Pada dasarnya PT. PLPJ mengelola sistem pembangkitan listrik dengan jenis PLTMG yang menggunakan mesin gas sebagai penggerak sebuah generator sinkron yang digerakkan oleh gas alam dan udara. Pada gambar dibawah ini, merupakan sebuah diagram satu garis sistem kelistrikan pendistribusian yang telah disederhanakan dari aplikasi WOIS (Wartsila Operation Interface System) yang terdapat pada monitoring di ruang operator. Terdapat 2 buah unit 
generator sinkron dengan kapasitas 7,744 MW yang kemudian akan disalkurkan menuju trafo daya (Step up) $11 \mathrm{kV}$ menjadi $20 \mathrm{kV}$ yang lalu didistribusikan ke 3 buah penyulang yang dilayani oleh PT.PLPJ yaitu : Fokker dan Airbus (G.I Seduduk Putih), Boeing (G.I Borang). Berikut merupakan sebuah simulasi single line diagram yang telah disederhanakan mengikuti petunjuk diagram sat ugaris sistem WOIS menggunakan aplikasi ETAP 12.6.

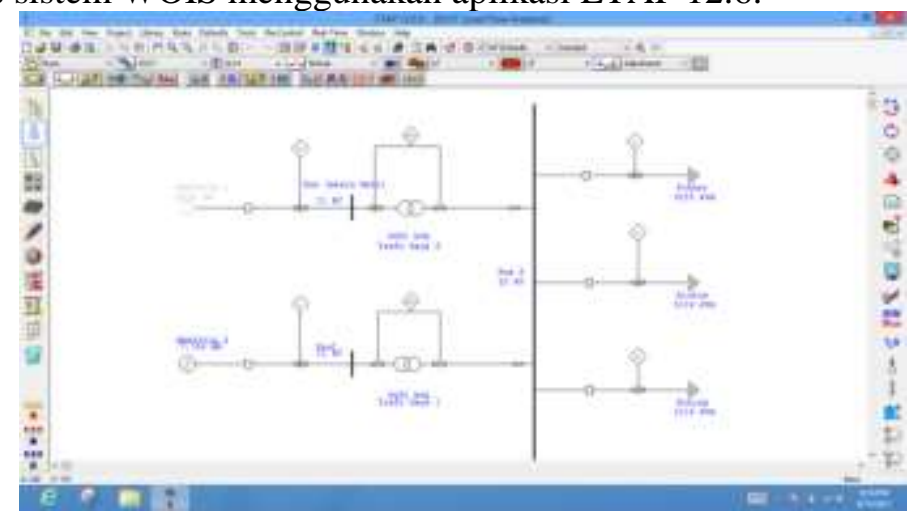

Gambar 1. SLD Berbasis ETAP 12.6

\section{HASIL DAN PEMBAHASAN}

\section{Perhitungan Rugi-rugi Total}

Dari data pembebanan yang telah tertera diatas, dapat diperoleh sebuah langkah selanjutnya yaitu mencari rugi - rugi total, namun sebelum mencari rugi-rugi total terlebih dahulu mencari besarnya impedansi generator menggunakan persamaan (1)

A. Impedansi

$$
\begin{aligned}
\mathrm{Z}_{1}=\mathrm{Z}_{2}=\mathrm{Z}_{3} & =\frac{V}{I \cdot \sqrt{3}} \\
& =\frac{11000 \mathrm{~V}}{508,1 A \cdot \sqrt{3}} \\
& =\frac{11000}{880} \\
& =12,5 \Omega
\end{aligned}
$$

Setelah nilai impedansi didapatkan, maka dari itu akan dilakukan perhitungan resistansi generator menggunakan persamaan (2)

$$
\begin{aligned}
\mathrm{R} & =\mathrm{Z}{ }^{\prime} \times \operatorname{Cos} \phi \\
& =12,5 \Omega \times 0.84 \\
& =10,5 \Omega
\end{aligned}
$$

Setelah mendapatkan resistansi generator maka akan dilanjutkan dengan perhitungan rugi - rugi generator dengan menggunakan persamaan (10).

- $\quad$ Rugi Tembaga $=\mathrm{I}^{2} \cdot \mathrm{R}$

$$
\begin{aligned}
& =(113)^{2} \cdot 10,5 \Omega \\
& =134074,5 \text { Watt } \\
& =0,134 \mathrm{MW}
\end{aligned}
$$

- Rugi Beban Penuh $=\frac{\text { Rugi Tembaga }}{30 \%}$

$$
\begin{aligned}
& =\frac{0.134}{0,3} \\
& =0.447 \mathrm{MW}
\end{aligned}
$$

Besar rugi mekanik berada dalam range 10 sampai $20 \%$ dari rugi total pada beban penuh, dikarenakan kondisi lapangan generator memikul saat beban penuh $100 \%$, maka dipilihnya $20 \%$. 
- Rugi Mekanik $=20 \% \times$ Rugi Beban Penuh

$$
\begin{aligned}
& =0,2 \times 0.447 \mathrm{MW} \\
& =0.089 \mathrm{MW}
\end{aligned}
$$

Besar rugi besi berada dalam range 20 sampai $30 \%$ dari rugi total pada beban penuh, dikarenakan kondisi lapangan generator memikul saat beban penuh $100 \%$, maka dipilihnya $30 \%$.

- Rugi Besi $=30 \% \times$ Rugi Beban Penuh

$$
\begin{aligned}
& =0,3 \times 0.447 \mathrm{MW} \\
& =0,134 \mathrm{MW}
\end{aligned}
$$

- $\quad \Sigma$ Rugi Total $=($ Rugi Tembaga + Rugi Mekanik + Rugi Besi $)$

$$
\begin{aligned}
& =0,134+0,089+0,134 \\
& =0,358 \mathrm{MW}
\end{aligned}
$$

\section{Perhitungan Efisiensi Generator}

Perhitungan efisiensi generator merupakan perbandingan daya keluaran dengan daya masukan yang dikalikan dengan persentase, sebagaimana tertera pada persamaan 2.10. Berdasarkan data pembebanan generator maka didapatkan persentase efisiensi generator sebagai berikut :

$\eta=\frac{P_{\text {out }}}{P_{\text {in }}} \times 100 \%$

$\mathrm{P}_{\text {in }}=\mathrm{P}_{\text {out }}+\mathrm{P}_{\text {rugi-rugi }}$

$\mathrm{P}_{\text {out }}=3 . \mathrm{V}_{\mathrm{ph}} \cdot \mathrm{I}_{\mathrm{ph}} \cdot \cos \varphi$

$\mathrm{P}_{\text {Out }}=3 \cdot \frac{20900}{\sqrt{3}} \cdot 113 \cdot 0,84$

$\mathrm{P}_{\text {Out }}=3.120066 .113 .0,84$

$\mathrm{P}_{\text {Out }}=3,435 \mathrm{MW}$

$\eta=\frac{P_{\text {out }}}{P_{\text {out }}+P_{\text {rugi-rugi }}} \times 100 \%$

$\eta=\frac{3,435 M W}{3,435 M W+0,357 M W} \times 100 \%$

$\eta=\frac{3,435 M W}{3,792 M W} \times 100 \%$

$\eta=0,9058 \times 100 \%$

$\eta=90.58 \%$

Hasil Perhitungan Efisiensi Pada Penyulang Boeing

Pada gambar dibawah ini. Pembebanan tertinggi pada penyulang boeing berada pada pukul 08:30 sebesar 3.700 MW dengan efisiensi terendah $89.96 \%$.

\section{Efisiensi Penyulang Boeing}

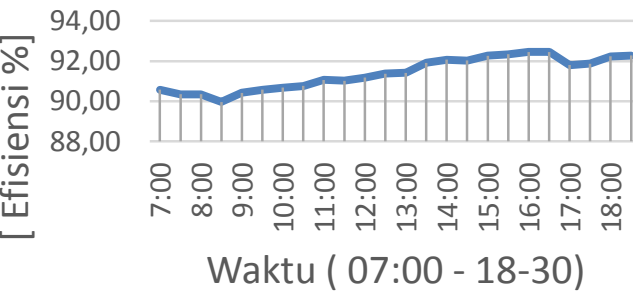

Gambar 2. Efisiensi Pada Penyulang Boeing 
Sedangkan pembebanan terendah berada pada pukul 22:00 sebesar 2.633 MW yang dimana tidak menunjukkan efisiensi tertinggi sebagaimana pada pukul 04:30 sebesar 92.93\% dengan pembebanan 2.687 MW yang malah menunjukkan efisiensi tertinggi yang dikarenakan rendahnya nilai cosphi pada pukul 22:00.

\section{EFisiensi Penyulang Boeing}

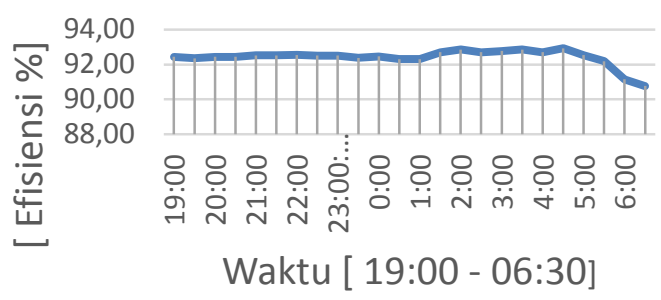

Gambar 3. Efisiensi pada penyulang boeing

\section{Hasil Perhitungan Efisiensi Pada Penyulang Airbus}

Pada gambar 4 pembebanan terkecil berada pada pukul 07:00 sebesar 1.672 MW dengan menunjukkan efisiensi tertinggi sebesar $95.18 \%$

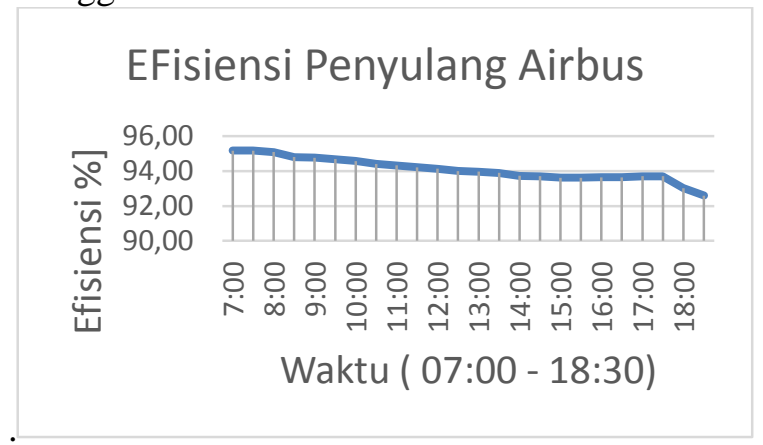

Gambar 4. Efisiensi pada penyulang airbus

Sedangkan Pembebanan terbesar berada pada pukul 19:00, 20:00-21:30 sebesar 2.651 MW dengan menunjukkan efisiensi terendah $92.52 \%$.

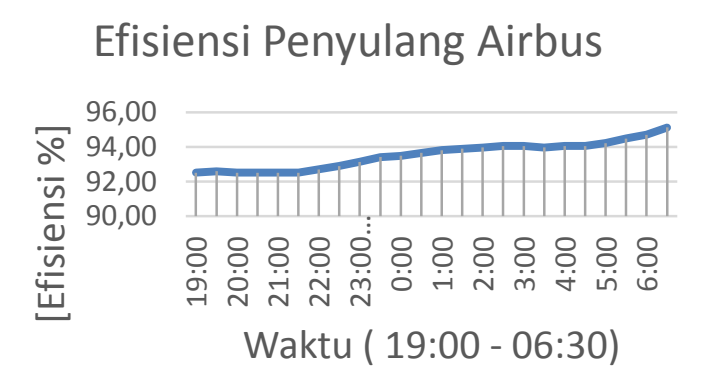

Gambar 5. Efisiensi pada penyulang airbus

\section{Hasil Perhitungan Pada Penyulang Fokker}

Pada gambar 6. pembebanan terkecil berada pada pukul 09:00 sebesar 1.692 MW dengan menunjukkan efisiensi tertinggi sebesar $95.18 \%$. 


\section{Efisiensi Penyulang Fokker}

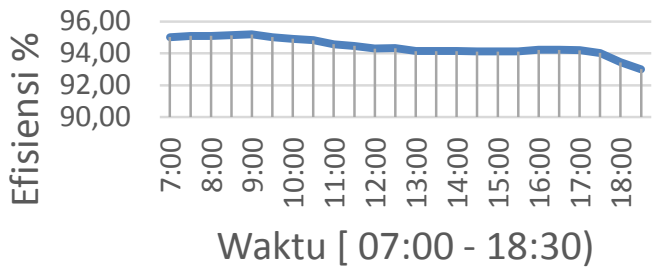

Gambar 6. Efisiensi pada penyulang fokker

Sedangkan pembebanan terbesar berada pada pukul 21:00 sebesar 2.682 MW dengan menunjukan efisiensi terendah $92.44 \%$

\section{Efisiensi Penyulang Fokker}

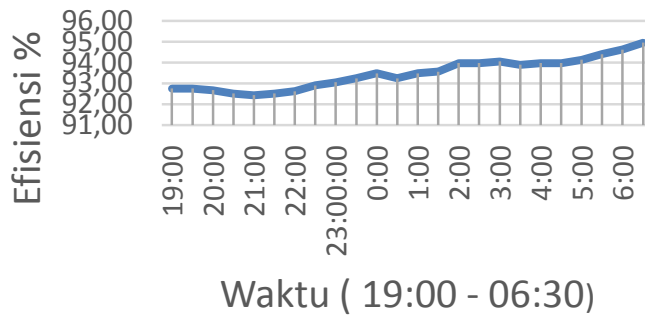

Gambar 7. Efisiensi pada penyulang fokker

\section{Grafik Fluktuasi Beban Terhadap Efisiensi Total Pada Generator}

pembebanan terkeecil pada generator berada pada pukul 07:00 dengan pembebanan sebesar 6.841 MW yang dimana belum menunjukkan efisiensi tertinggi sebagaimana pada pukul 05:30 dengan pembebanan 7.139 MW yang malah menunjukkan efisiensi tertinggi. Hal tersebut dikarenakan nilai rendahnya nilai cos phi pada pukul 07:00.

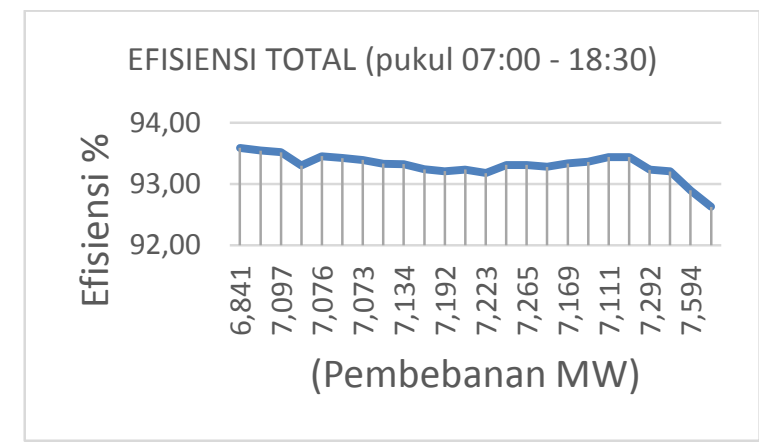

Gambar 8. Efisiensi Total Generator

Sedangkan pembebanan terbesar berada pada pukul 21:00 sebesar 7.984 MW dengan menunjukkan efisiensi terendah sebesar $92.90 \%$. 


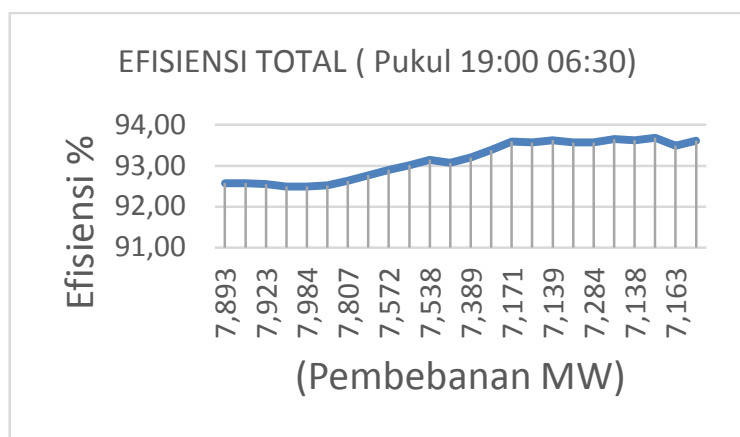

Gambar 9. Efisiensi Total Generator

\section{Data Beban Puncak Dan Diluar Beban Puncak}

Dari hasil perhitungan diatas, dapat diambil data beban puncak dan data diluar beban puncak dari melihat pembebanan generator dari terendah ke tertinggi.

Tabel 3. Beban puncak \& diluar beban puncak

\begin{tabular}{|c|c|c|c|}
\hline \multirow{2}{*}{ Penyulang } & \multicolumn{2}{|c|}{ Diluar Beban Puncak (07:00) } & Beban puncak (21:00) \\
\cline { 2 - 4 } & $\mathrm{I}$ & MW & I \\
\hline Boeing & 113 & 3.436 & 87 \\
\hline Airbus & 55 & 1.672 & 87 \\
\hline Fokker & 57 & 1.733 & 88 \\
\hline Total & \multicolumn{2}{|c|}{$6.841 \mathrm{MW}$} & $7.984 \mathrm{MW}$ \\
\hline
\end{tabular}

Pada ETAP 12.6 dapat dilihat sebuah data hasil running loadflow yang mengeluarkan sebuah aliran daya berserta arus yang mengaliri pada setiap penyulang.

Tabel 4. Data beban berdasarkan data ETAP 12.6

\begin{tabular}{|c|c|c|c|c|}
\hline \multirow{2}{*}{ Penyulang } & \multicolumn{2}{|c|}{ Diluar Beban Puncak (07:00) } & \multicolumn{2}{|c|}{ Beban puncak (21:00) } \\
\cline { 2 - 5 } & $\mathrm{I}$ & MW & $\mathrm{I}$ & MW \\
\hline Boeing & 103 & 2.890 & 80 & 2.244 \\
\hline Airbus & 50 & 1.407 & 80 & 2.244 \\
\hline Fokker & 52 & 1.457 & 80 & 2.270 \\
\hline Total & \multicolumn{3}{|c}{$5.754 \mathrm{MW}$} & \multicolumn{3}{c}{$6.758 \mathrm{MW}$} \\
\hline
\end{tabular}

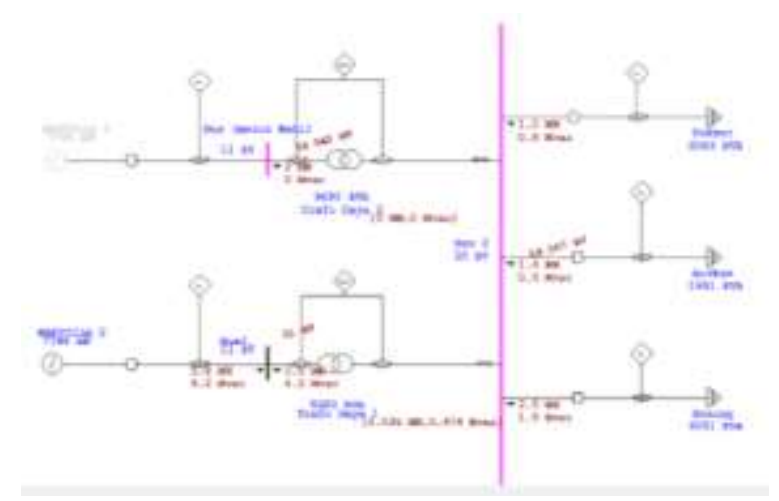

Gambar 10. Load Flow Analysis 


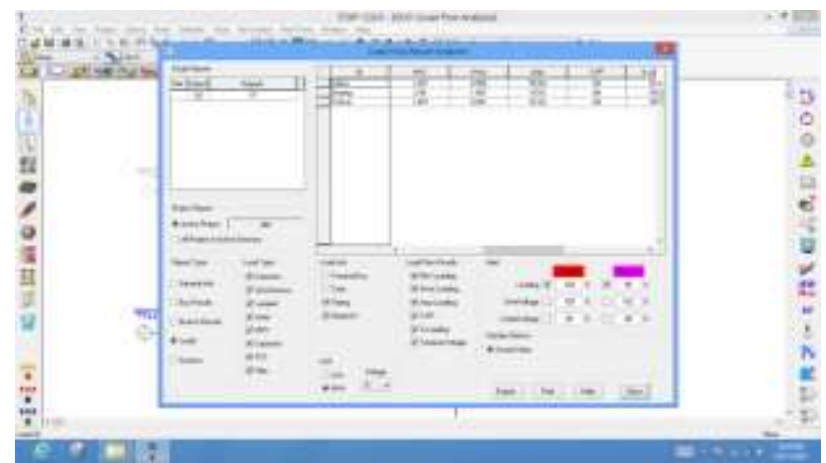

Gambar 11. Load Flow Result Analyzer

Hasil Perhitungan Efisiensi Berdasarkan Pembagian waktu

Tabel 5. Perhitungan Manual

\begin{tabular}{|c|c|c|c|}
\hline \multirow{2}{*}{ Beban } & Penyulang & $\Sigma$ Ptotal (MW) & Efisiensi (\%) \\
\hline \multirow{3}{*}{$\begin{array}{c}\text { Diluar Beban } \\
\text { Puncak (07:00) }\end{array}$} & Boeing & 0.358 & 90.58 \\
\cline { 2 - 4 } & Airbus & 0.085 & 95.18 \\
\cline { 2 - 4 } & Fokker & 0.091 & 95.01 \\
\cline { 2 - 4 } & \multicolumn{2}{|c|}{ Rata-rata } & 93.59 \\
\hline \multirow{2}{*}{$\begin{array}{c}\text { Beban Puncak } \\
(21: 00)\end{array}$} & Boeing & 0.214 & 92.52 \\
\cline { 2 - 4 } & Airbus & 0.214 & 92.52 \\
\cline { 2 - 4 } & Fokker & 0.219 & 92.44 \\
\hline & \multicolumn{3}{|c|}{ Rata-rata } \\
\hline
\end{tabular}

Tabel 6. Perhitungan Berdasarkan Data ETAP 12.6

\begin{tabular}{|c|c|c|c|}
\hline Beban & Penyulang & $\Sigma$ Ptotal (MW) & Efisiensi (\%) \\
\hline \multirow{4}{*}{$\begin{array}{l}\text { Diluar } \\
\text { Beban } \\
\text { Puncak } \\
(07: 00)\end{array}$} & Boeing & 0.296 & 90.70 \\
\hline & Airbus & 0.069 & 95.32 \\
\hline & Fokker & 0.074 & 95.16 \\
\hline & \multicolumn{2}{|c|}{ Rata-rata } & 93.72 \\
\hline \multirow{4}{*}{$\begin{array}{c}\text { Beban } \\
\text { Puncak } \\
(21: 00)\end{array}$} & Boeing & 0.184 & 92.42 \\
\hline & Airbus & 0.184 & 92.42 \\
\hline & Fokker & 0.179 & 92.69 \\
\hline & \multicolumn{2}{|c|}{ Rata-rata } & 92.51 \\
\hline
\end{tabular}

\section{KESIMPULAN}

Terjadinya fluktuasi beban pada generator akan mempengaruhi sebuah efisiensi generator sinkron. Namun, faktor lain yang menentukan efisiensi sebuah generator juga dapat dilhat dari tinggi rendahnya nilai cos phi pembebanan. Sebagaimana pada hasil perhitungan dalam 2 hari tersebut terdapat nilai cos phi yang <0.85 (0.84 dan 0.80) yang dimana PT. PLPJ menggunakan nilai Cos phi 0.85. hal tersebut mengakibatkan turunnya efisiensi sebagaimana kita ketahui bahwa standar efisiensi generator ini dari 97,55\% menjadi (93.59\% dan 93.56\%) walaupun kecilnya pembebananan pada generator. Dengan dilakukannya perhitungan saat beban puncak dan diluar beban pucak dalam 2 hari tersebut, terdapat pembebananan generator saat beban puncak melebihi kapasitas beban generator dari 7.744 MW menjadi 7.984 MW yang dimana menunjukkan efisiensi terendah sebesar $92.49 \%$. Sedangkan saat diluar beban puncak terdapat pembebanan 6.841 MW menunjukkan efisiensi sebesar $93.59 \%$. Efisiensi pada tiap-tiap penyulang akan 
berbanding lurus dengan jumlah pembebanan, apabila pada jam tersebut pembebanan pada tiaptiap penyulang cenderung besar maka efisiensi total pada generator akan menurun. Begitupula sebaliknya, apabila pembebanan pada jam tersebut pembebanan pada tiap-tiap penyulang cenderung kecil maka efisiensi total pada generator akan meingkat.

\section{DAFTAR PUSTAKA}

[1]. Hermawan Cahyadi, D, "Analisa Perhitungan Efesiensi turbine Generator QFSN-300-220B Unit 10 dan 20 PT. PJB UBJOM PLTU Rembang," no. June, pp. 5-8, 2015.

[2] A. Hidayat, "Analisis pengaruh beban terhadap efisiensi generator PLTU PT. Lestari Banten Energi," 2018.

[3] M. Muharrir and I. Hajar, "Analisis Pengaruh Beban Terhadap Efisiensi Generator Unit 2 PLTP PT. Indonesia Power UPJP Kamojang,” Kilat, vol. 8, no. 2, pp. 93-102, 2019, doi: 10.33322/kilat.v8i2.643.

[4] M. Noer, "Analisa Pengaruh Pembebanan Terhadap Efisiensi Generator Di Pltg Borang Dengan Menggunakan Software Matlab," J. Ampere, vol. 2, no. 2, p. 103, 2017, doi: 10.31851/ampere.v2i2.1774.

[5] Y. Rijono, Dasar Teknik Tenaga Listrik. Yogyakarta, Indonesia: Penerbit Andi, 2002.

[6] Z. Anthony, Mesin listrik arus bolak-balik. Indonesia: Penerbit Andi.Yogyakarta, 2013.

[7] S. Sudirham, Analisa Rangkaian Listrik, Jilid 1. Darpublic, kanayakan Bandung.

[8] K. Ramesh. A, Electrical Engineering. 2010.

[9] M. Kadaffi, Perancangan Sistem Tenaga Listrik. Indonesia: Pusat Pengembangan Bahan Ajar Universitas Mercu Buana, 2011.

[10] A. Firmansyah, "Modul Pelatihan ETAP.” Politeknik Negeri Sriwijaya, 2014. 